\title{
PENGEMBANGAN APLIKASI KATEGORI RSS (RICH SITE SUMMARY) BERBASIS WEB
}

\author{
Andrea Stevens Karnyoto \\ ${ }^{1}$ Fakultas Teknik, Universitas Kristen Indonesia Toraja \\ email: andre@ukitoraja.ac.id
}

\begin{abstract}
Kebutuhan masyarakat Indonesia terhadap informasi sangat besar jika dilihat dari semakin berkembangnya media-media berita online dan semakin banyaknya situs-situs website yang sangat sering melakukan pembaharuan berita. Dibutuhkan fasilitas untuk memberikan kemudahan dalam melakukan klasifikasi kategori berdasarkan kata-kata yang populer sesuai yang terdapat pada Google Trends agar mempermudah pencari berita membaca berita-berita yang terkait satu dengan yang lainnya baik pada media yang sama maupun lintas media. Metode yang digunakan untuk membuat kategori dengan cara membaca RSS(Rich Site Summary) dan mengelompokkannya berdasarkan kata-kata yang terdapat didalamnya, metode tersebut dieksekusi dengan menjalankan crontab secara berkala sehingga server dapat membaca RSS dan memprosesnya dan melakukan klasifikasi kategori untuk seluruh website media yang telah didaftar sebelumnya, medote yang digunakan untuk melakukan klasifikasi kategori adalah menggunakan metode keterkaitan kata antara satu kata dengan kata-kata yang lainnya. Hasil dari proses klafisikasi kategori akan ditampilkan pada halaman website yang menarik dan sistem pencarian yang mudah bagi pengguna.
\end{abstract}

Keywords: RSS, Informasi, Kategori

\section{PENDAHULUAN}

Kebutuhan informasi masyarakat Indonesia sangat tinggi, baik itu berita politik, sosial budaya, infotaiment, gaya hidup dan lain sebagainnya. Bahkan saat ini di Indonesia terdapat banyak websitewebsite berita yang memiliki jurnalis yang tersebar diseluruh indonesia seperti kompas.com, detik.com, okezone.com dan lain-lain, selain itu juga banyak website-website pemerintah aktif melakukan penambahan atau pembaharuan berita seperti dikti.go.id, mahkamahagung.go.id, polri.go.id, dan lain sebagainya. Merujuk pada alexa.com tanggal 4 April 2015 untuk website terpopuler di Indonesia adalah detik.com pada posisi 6, kompas.com pada posisi 12 dan liputan6.com posisi 13. Informasi dari alexa.com tersebut menjadi acuan bahwa situs berita sangat diminati masyarakat Indonesia. Untuk situs-situs pemerintah seperti dikti.go.id berada diperingkat 218, polri.go.id berada diperingkat 1116 .

Setiap website yang dibuat dengan baik memiliki RSS(Rich Site Summary atau Really Simple Syndication) yang berguna memudahkan menambah Trafik dan mempermudah menyebarluaskan didunia maya serta masih banyak fungsi lainnya. RSS memberikan para pengunjung untuk dapat berlangganan secara gratis dan mengikuti perkembangan situs setiap saat. RSS dapat dibuat secara manual oleh pembuat berita tiap kali menulis berita atau dibuat dengan RSS generator yang biasanya terdapat pada CMS (Content management System) yang digunakan.

RSS (Rich Site Summary) yang awalnya RDF Site Summary sering disebut Really Simple Syndication, menggunakan sebuah format feed web standar untuk mempublikasikan informasi yang sering diperbarui seperti entri blog, berita utama, audio maupun video. Sebuah dokumen RSS (yang disebut "feed", "web feed", atau "channel"). RSS terdiri dari berita, teks yang diringkas, metadata, juga dapat seperti tanggal penerbitan dan nama penulis.

RSS dapat dijadikan bahan untuk mempermudah melakukan klasifikasi kategori berita, teks yang diringkas dapat dikategorikan menggunakan urutan kata yang terdapat didalamnya atau dengan mengkategorikan dengan kata-kata yang sedang populer saat ini. Kata-kata yang sedang populer dapat dilihat pada Google Trends. 
Dibutuhkan sebuah penelitian ini untuk melakukan pengembangan aplikasi berbasis web untuk mengklasifikasikan menjadi kategori menurut kata-kata yang populer pada berita atau informasi dari banyak situs website yang bertujuan memudahkan masyarakat dalam mencari berita atau informasi yang terkait satu dengan yang lain dari website yang berbeda-beda.

Berdasarkan uraian pada latar belakang di atas, maka penulis tertarik untuk mengambil judul: "Pengembangan Aplikasi Kategori RSS (Rich Site Summary) berbasis Web".

\subsection{Rumusan Masalah}

Bagaimana mengembangkan aplikasi website yang dapat mengkategorikan RSS berdasarkan kata-kata populer yang terkandung didalamnya pada situs berita, yang berbahasa Indonesia.

\subsection{Tujuan Penelitian}

Untuk membuat aplikasi website yang mengkategorikan berdasarkan kata-kata yang populer pada beberapa situs website berbahasa Indonesia berdasarkan susunan kata menggunakan RSS beberapa situs website dan mencatat jumlah pengunjung aplikasi situs website tersebut.

\subsection{Manfaat Penelitian}

Mempermudah mencari informasi berita dari banyak website dengan hanya membuka satu situs website saja.

\subsection{Batasan Masalah}

Ruang lingkup penelitian ini adalah.

1. Mengkategorikan RSS untuk website-website indonesia saja.

2. Mengkategorikan RSS ini dibuat menggunakan Yii2 Framework.

\section{RSS (Rich Site Summary)}

Web (WWW) merupakan jaringan terbesar dan bisa dibilang repositori yang paling kompleks dalam hal konten pada masa sekarang ini. Informasi di web menggunakan berbagai media, dan saat ini dominasi oleh text dan gambar yang memiliki data dan meningkatkan kehadiran modalitas lain seperti video dan audio. Interaksi manusia konten di web-media yang kaya merupakan topik penting dari penelitian[7]. Saat ini adalah era web 2.0 dimana setiap orang dapat membuat dan memperbarui konten, dan semua orang dapat melakukan unggah berita situs web pribadi dengan mudah, sehingga para pengguna internet sangat sulit untuk mengumpulkan informasi berharga bagi dirinya dari situs web yang berbeda-beda. Dengan RSS, orang dapat membaca informasi dari sumber yang berbeda dengan dengan cara mudah dan cepat dengan menggunakan sebuah aplikasi seperti RSS reader. Namun, sebagian besar pembaca RSS hanya menampilkan item dalam urutan kronologis, yang tidak bekerja dengan baik ketika pengguna dibanjiri terlalu banyak item dalam feed[2]. Web 2.0 memberikan banyak aktivitas untuk e-Learning termasuk dari perusahaanperusahaan Internet besar seperti Google dan Apple[4].

File RSS pada dasarnya format XML biasa. File RSS itu sendiri relatif mudah dibaca baik oleh proses otomatis dan manusia. RSS ini dapat ditempatkan pada setiap protokol komunikasi yang sesuai untuk pengambilan berkas, seperti http atau ftp, dan program pembaca akan menggunakan informasi tersebut untuk menyajikan tampilan yang rapi untuk pengguna akhir. 


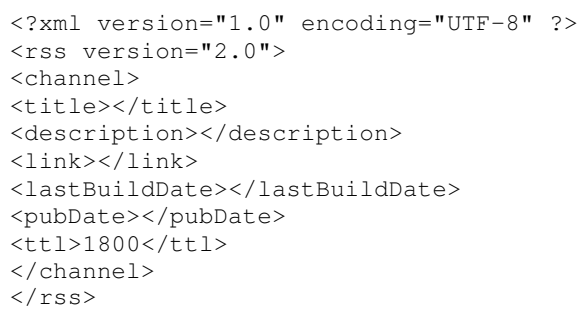

Gambar 1. Contoh RSS

\section{METODE PENELITIAN}

\subsection{Lokasi dan Waktu Penelitian}

Penelitian dilakukan di Universitas Kristen Indonesia dan dilakukan selama 5 bulan.

\subsection{Sumber Data}

Sumber data diambil dari RSS situs-situs berita online, pemerintah, perusahaan dan pribadi yang sering melakukan pengunggahan atau penambahan serta berbaharuan berita.

\subsection{Tahap Penelitian}

1) Melakukan studi literatur dengan melakukan studi dari buku-buku pustaka, jurnal-jurnal ilmiah dan aritkel-artikel dari internet terkait dengan masalah yang dibahas.

2) Langkah-langkah dalam tahapan penelitian:

a) Analisis sistem mendefinisikan fitur-fitur sistem, membaut perencanaan.

b) Melakukan observasi kata-kata yang dapat menjadi kategori baik itu merupakan kata-kata populer ataupun kata-kata yang khusus.

3) Melakukan pengunggahan pada hosting.

a) Pendaftaran nama domain http://www.rssja.com, jika nama telah terpakai maka penulis akan mencari nama domain lain.

b) Pendaftaran hosting unlimited.

c) Unggah seluruh aplikasi dan database yang telah dibuat.

4) Melakukan pendaftaran pada mesin-mesin pencari seperti google, bing, yahoo dan lain sebagainya.

5) Melakukan pencatatan terhadap jumlah pengunjung dan melakukan update kata-kata populer tiap minggu.

\subsection{Strategi Pengembangan Sistem}


Pengembangan sistem ini dibuat oleh ketiga penulis sampai dengan penulisan laporan. Untuk studi ide dan metode dilakukan oleh penulis pertama dan pembuatan laporan dilakukan oleh penulis kedua dan ketiga.

\subsection{Gambaran Umum Sistem}

\subsubsection{Perangkat Keras Sistem}

Sistem menggunakan perangkat keras intel xeon x64 dengan minimal memori 4 GB dan kapasitas hardisk 500GB.

\subsubsection{Perangkat Lunak Sistem}

Perangkat lunak menggunakan Apache 2.2.24, PHP 5.3.26, MySQL 5.1.7cl, phpMyAdmin 4.2.11, OpenSSL 1,0.1j. Linux Kernel 2.6.32-531.29.2. CPanel 11.48.2 (build 3).

\subsection{Desain Sistem}

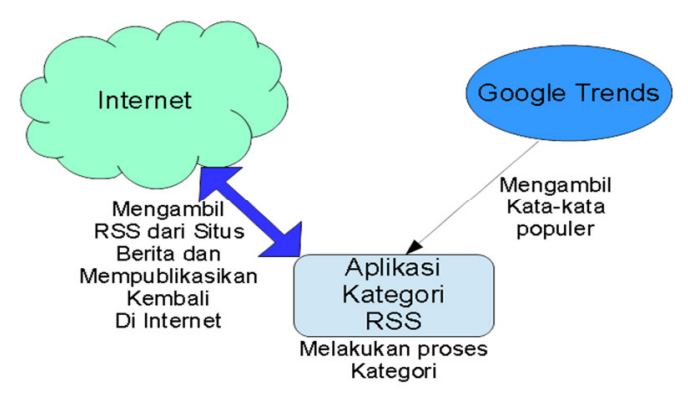

Gambar 2 Hubungan Aplikasi Kategori RSS

Gambar 2 memperlihatkan bahwa sinkronisasi dengan google trends dengan menjalankan crontab pada sistem Aplikasi Kategori RSS secara periodik tiap 12 jam sekali sehingga daftar kata-kata populer dapat terus diperbaharui. Aplikasi Kategori RSS melakukan pembaharuan pembacaan RSS tiap situs website yang telah terdaftar juga dilakukan secara periodik setiap 6 jam. Setalah melakukan proses pembaharuan dan membuat kategori maka Aplikasi Kategori RSS akan menampilkan di internet.

Aplikasi Kategori RSS melakukan klasifikasi kategori kata-kata berjalan background sehingga tidak mempengaruhi performa saat web diakses. Selain itu juga berjalan secara paralel untuk beberapa pembaca website yang dituju.

\section{HASIL DAN PEMBAHASAN}

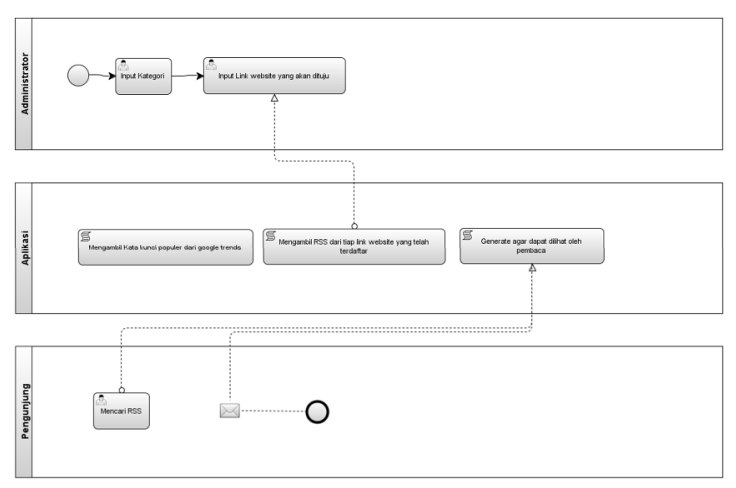

Gambar 3 Business Process Model and Notation 
Dari gambar 3 dapat disimpulkan bahwa tugas dari administrator adalah melakukan penginputan kategori dan memasukkan daftar link RSS yang rutin akan dibaca. Sementara aplikasi akan secara otomatis melakukan pembaharuan baik itu kata kunci dari google trends maupun dari link-link yang telah terdaftar. Pengunjung dapat mencari berita-berita dari RSS yang telah terdaftar.

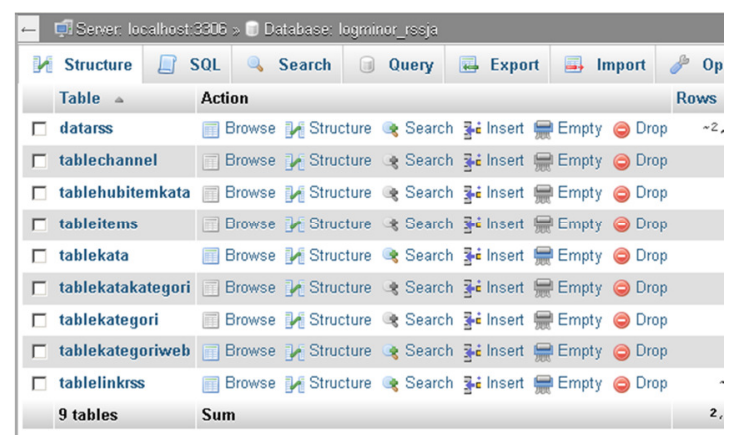

Gambar 4. Tabel yang digunakan dalam program

Data dimasukkan dalam MySql database, untuk itu digunakan phpmyadmin.

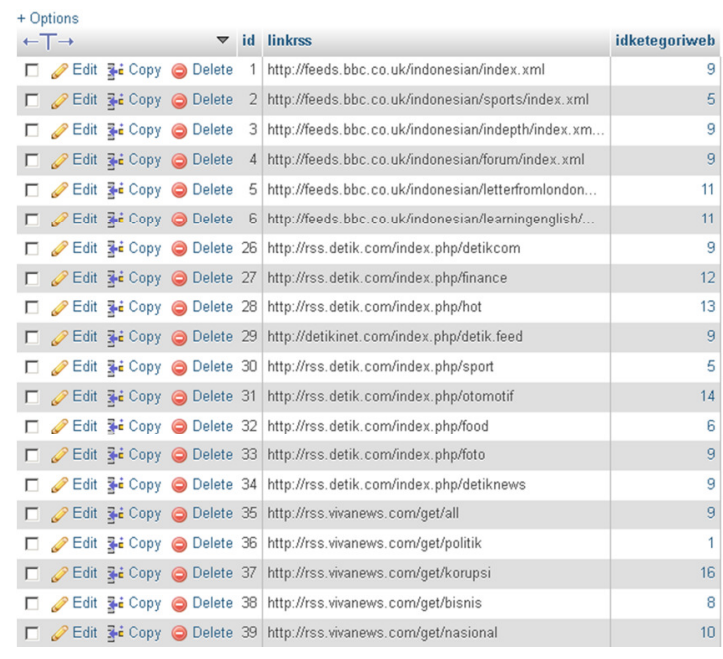

Gambar 5. Daftar RSS yang akan degenerate

Gambar diatas adalah tabel yang menunjukkan link situs RSS yang akan diproses setiap dua kali sehari, jumlahnya akan terus bertambah sehingga pembaca akan terus mendapatkan informasi yang terbaru.

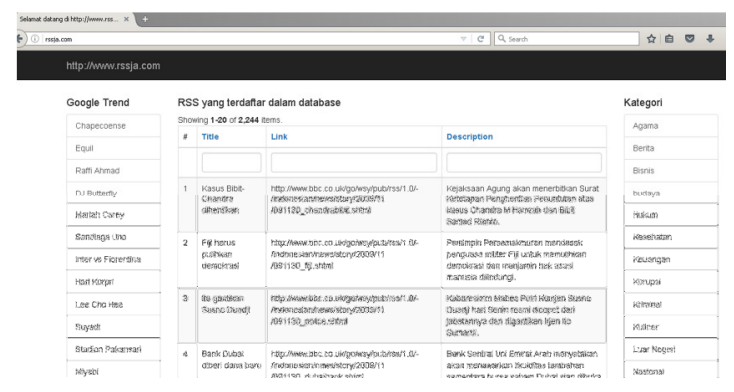

Gambar 6. Antarmuka program ke pengunjung

Dengan program ini, pengunjung dapat melihat seluruh hasil program yang menampilkan baik kategori, trend keyword google maupun RSS yang telah terdaftar. 


\section{KESIMPULAN}

Dengan Pengembangan Aplikasi Kategori RSS (Rich Site Summary) berbasis Web memberikan kemudahan bagi pencari berita agar melihat berita lebih luas dengan hanya membuka sebuah situs web. Aplikasi ini masih harus lebih dikembangkan lagi agar dapat memberikan kontribusi yang besar bagi masyarakat dengan memberikan link pada tiap kategori dan kata kuncinya.

\section{REFERENSI}

[1] Alexander Makarov, 2013, "Yii Application Development Cookbook, 2nd Edition", Packt Publishing.

[2] Cansheng Ji dan Jingyu Zhou, 2010, "A Study on Recommendation Features for an RSS Reader", International Conference on Cyber-Enabled Distributed Computing and Knowledge Discovery.

[3] Chengling Zhao, Liyong Wan, dan Ying Yu, 2006, "Construction of a Distributed Learning Resource Management System Based on RSS Technology", 36th ASEE/IEEE Frontiers in Education Conference.

[4] Kalpana S. Kumaran dan Ms. Veni M. Nair, 2010, "Future Trends in E-Learning", 4th International Conference on Distance Learning and Education (ICDLE).

[5] Mark Safronov dan Jeffrey Winesett, 2014, "Web Application Development with Yii 2 and PHP", Paperback.

[6] Matt Zandstra, 2013, "PHP Objects, Patterns, and Practice", Paperback.

[7] Rahul Singh dan Bibek D. Bhattarai, 2010, "Determining User Information Goals In MediaRich Web Sites By Rethinking Information Scent Theory", ICME 2010. 